\title{
A Comparative Demonstration and Analysis of File Sharing Applications on Android Mobile Devices
}

\author{
Anas Irfan \\ Department of Computer \\ Science Engineering \& Technology \\ Jamia Hamdard \\ New Delhi
}

\author{
Aqeel Khalique \\ Department of Computer \\ Science Engineering \& Technology \\ Jamia Hamdard \\ New Delhi
}

\begin{abstract}
Recently, Smartphone users have frequent need for share files and data such as (applications, audio, video, images even contacts) with other Smartphone users having same type of compatible device on the go, there are various free and paid file sharing applications available in the market for this very purpose, these file sharing applications mainly use WLAN (Wi-Fi Hotspot) for sharing files by creating an Ad-hoc wireless network and share files with other users within their vicinity.

In this paper, comparative study and analysis of file sharing applications has been performed and presented. These file sharing applications enable the users for faster sharing rate among them through WLAN. They provide ease of access among multiple compatible devices. Several tests have been conducted including transferring several types of files and results have been gathered and these results are used in the analysis. A comparative analysis has also been done and the challenges or issues that are present in the concerned file sharing applications have been mentioned.
\end{abstract}

The work primarily focuses on the commonly used file sharing applications in Smartphone's worldwide namely SHAREit, Xender and Zapya.

\section{General Terms}

File Sharing, WLAN File Transfer.

\section{Keywords}

Mobile File Sharing Applications, File Sharing, Android File Sharing Applications, SHAREit, Zapya, Xender

\section{INTRODUCTION}

File sharing is transferring or sharing the digital data such as image, audio, video, document etc. stored on an electronic device (mobile, laptop etc.) with similar compatible electronic devices. Nowadays, file sharing is mostly done through wireless medium. Earlier, sharing of files or data between different electronic devices such as mobile phones, laptop, etc were done using traditional modes based on IR (Infrared Waves) or Bluetooth, but file sharing using IR and Bluetooth connectivity were time consuming because of their slow data transfer rate. As technology advancement took place users need these things like sharing files to be less time consuming with faster data transfer rate, the faster data transfer rate have been achieved through the use of wireless medium using WLAN.

In recent days, numerous applications were introduced in digital market which can transfer file among different mobile devices over WLAN. These applications are available as proprietary and open source for further advancement. Using these applications, one can share digital file with an interactive ease of access. These applications create a personal network among the communicating devices over Wi-Fi channel; however, the communicating parties must have same file sharing application and must be present within the operating range of Wi-Fi i.e. $25-30 \mathrm{~m}$.

According to statistical data, there are around 2.16 Billion active Smartphone (devices or) users in the world in $2016^{[1]}$ and there are around 700Million of the total 2.16Billion Smartphone users worldwide, who use SHAREit for sharing files $^{[2]}$ which is about $32.41 \%$ of the total Smartphone users worldwide, and around 450Million of the total 2.16Billion Smartphone users, who use Zapya for sharing files ${ }^{[3]}$ which is about $20.83 \%$ of the total Smartphone users worldwide, and around 330Million of the total 2.16Billion Smartphone users, who use Xender for sharing files ${ }^{[4]}$ which is about $15.28 \%$ of the total Smartphone users worldwide.

So, the total of $68.52 \%$ out of total 2.16 Billion Smartphone users worldwide use one of the three applications namely SHAREit, Zapya and Xender for sharing files, and there are remaining $31.48 \%$ out of total 2.16 Billion Smartphone users who use other mode for sharing files as shown in Figure1.

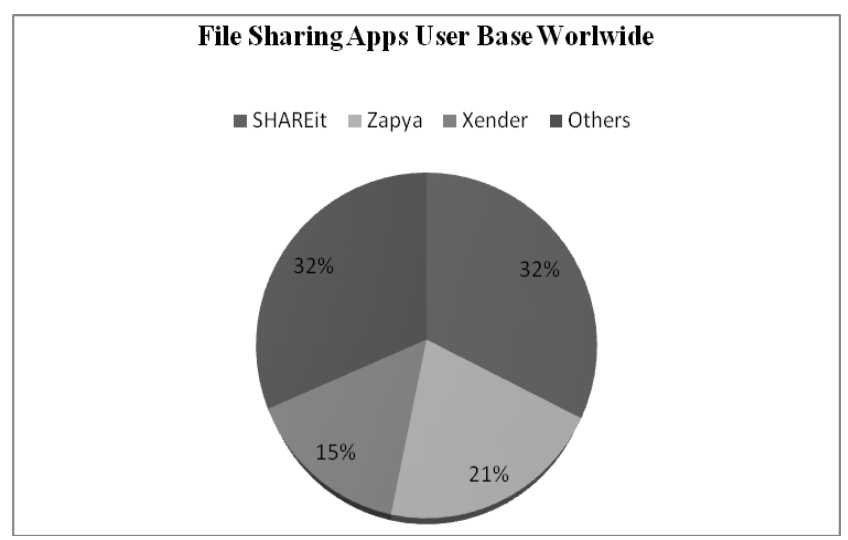

Fig 1: File Sharing User Base Worldwide

In this paper, a comparative study and analysis of three commonly used file sharing mobile applications namely SHAREit, Zapya and Xender has been done that run over Android platform and most commonly used by smart phone users. Current study has been restricted to these three mobile applications because of obvious limitations.

The further sections of the paper are categorized as follows: in Section 2 a background study of these applications has been done. In section 3, a comparative analysis based on the research findings has been presented. In section 4 , the results and analysis based on the research and findings has been 
presented, further in Section 5 and 6, the future work and conclusion has been presented respectively.

\section{FILE SHARING APPLICATIONS}

In this section, the commonly used applications namely SHAREit, Zapya and Xender for sharing media files (images, audio, video and document) through wireless peer-to-peer connection have been reviewed. All these applications use WLAN by creating ad-hoc Wi-Fi hotspot for the purpose of file sharing. In the subsections below, the growth, evolution, ease of access, features and issues of the mentioned mobile applications has been discussed.

\subsection{Shareit APPLICATION}

SHAREit is the world's fastest cross-platform file sharing android application used to share files through Wi-Fi compatible devices. It was developed by Lenovo Inc. and was first launched in China in June 2012. It is open source application and it allows inter-platform file sharing ${ }^{[2][5]}$. It is compatible on Windows PC, Windows Phone, Android, and iOS devices to transfer files directly through WLAN (Wi-Fi Hotspot). SHAREit allows user to share file to connected single user ranging from $1 \mathrm{MB}$ to $10 \mathrm{~GB}$.

Figure 2 shows screenshot of SHAREit application running on Android platform.

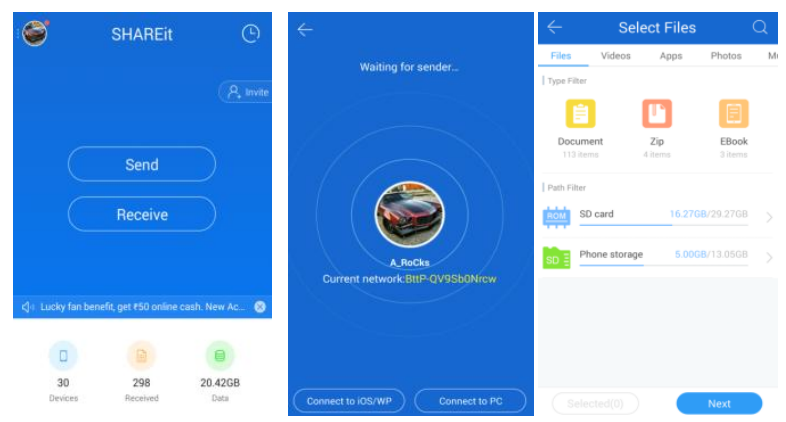

a)SHAREit Homepage b)Sending File Mode c)Receive File Mode

Fig 2: Screenshot of SHAREit

\subsubsection{Growth of SHAREit}

SHAREit application is launched in 2012 and became popular file sharing app. It got nearly 150-million users in India in one year of operation and over 500-million users worldwide. It works on WLAN (Wi-Fi Hotspot) technology, which does not rely on a pre-existing infrastructure. SHAREit is completely free and cost efficient. It allows the users to share files without Internet connection. It works incredibly fast about 200 times faster than Bluetooth and IR.

\subsubsection{Issues in SHAREit}

During the analysis phase, the focus was also made on the issues related to SHAREit. These issues are listed below:

- In the Android version of the SHAREit app, there is no password needed to join the hotspot leading to security issues.

- Other vulnerability is that SHAREit, traffic is in original form no encryption decryption technique is deployed, which result as these files and data in transit can be easily intercepted and altered.

- Attacker present within Wi-Fi range to connect into the LAN and monitor and view the files in transit.
- If a user is in receive mode, then anyone within the range can share file without any security mechanism (no confidentiality).

\subsection{Zapya Application}

Zapya is another famous file sharing application which is compatible across multiple operating systems (OS) and is freely available. It is developed by DEWMobiles Inc. for mobiles, tablets and PC through which one user can transfer the files such as images, audio, documents, videos, applications and games. It was initially developed for the Chinese market but later spread to neighboring countries such as Myanmar, Pakistan, and India ${ }^{[3]}$.

Through this application, files can be shared through WLAN to multiple users (maximum 4) at a time by creating a group. File sharing can be performed by creating a group and any other devices can be connected to this device as long as they are on the same network. When the devices get connected users can exchange the messages along with the files and applications. Zapya is developed as the fastest cross-platform wireless file sharing. Apart from this, Zapya gives a feature which allows connected user to access contents and device camera and device storage remotely.

Figure 3 shows screenshot of Zapya application running on Android platform. Figure 3(b) shows Zapya Application in file sending mode where one can select and choose files and create a group to share file with other users having Zapya. To receive files, user should scan the code or join the same group created by the sender. Both sender and receiver should be connected to the same ad-hoc WLAN network and stay within its range while sharing files.

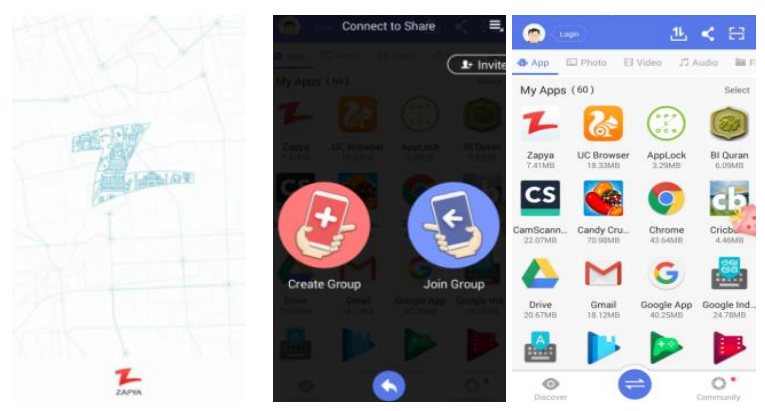

a)Zapya Homepage b)File Sending Mode c)File Receiving Mode

Fig 3: Screenshot of Zapya

\subsubsection{Growth of Zapya}

According to the experts, less than $40 \%$ of Smartphone users have mobile data plans and less than $30 \%$ of the users have access to internet. Zapya is a file sharing application which is used to share the files (documents, images, audio, and video) without internet through WLAN. Users of Zapya are not limited to the population of rural areas or developing countries where $\mathrm{Wi}-\mathrm{Fi}$ is less reliable, but also to the people residing in developing countries where mobile data is expensive. Zapya can benefit the users who cannot afford to share files through internet. Zapya is gaining hundreds of users every day. It is expected that there would be diverse range of Zapya users in the years to come ${ }^{[6]}$.

\subsubsection{Issues in Zapya}

During the analysis phase, the focus was also made to the issues related to Zapya file sharing application. These issues are listed below: 
- Data backup feature of Zapya does not work on all applications.

- Windows support unfortunately translates into malware and Zapya displays nothing.

- Complicated User Interface (Not User friendly interface)

\subsection{Xender Application}

Xender is an open source file sharing application which helps to connect two or more devices at a time for file sharing. Files such as images, music files, video files can be shared through the Xender application. It is originally launched in 2012 and was called as Flash Transfer. It is available in more than 30 different languages and the name was changed to Xender ${ }^{[4][7]}$. It is user friendly interface and share files of different size and format between connected devices through WLAN. The connected devices need to be in WLAN range while sharing files. Through this application, files can be shared through WLAN to multiple users (maximum 5) at a time by creating a group.

Figure 4 shows screenshot of Xender application running on Android platform. It also has gesture based control for file sharing, for example - shake to share the selected file with the connected group.
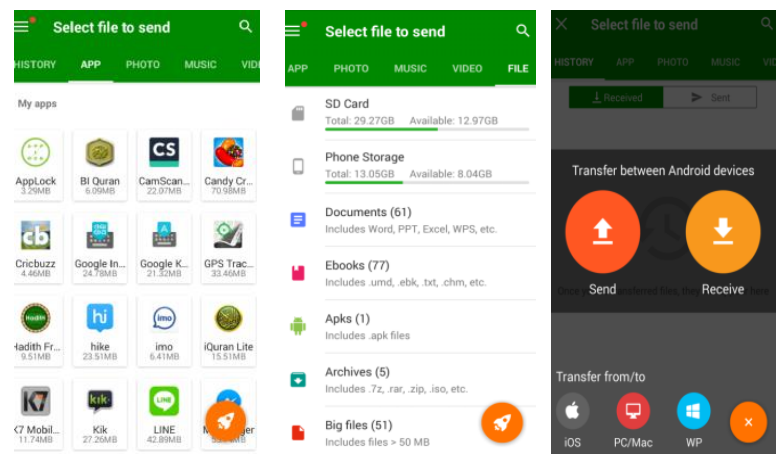

a)Xender Homepage b)File Sending Mode c)File Receive Mode

Fig 4: Screenshot of Xender

\subsubsection{Growth of Xender}

Xender was released in 2012 by the Xender team. In past few years, there were more than 80 million activated users globally and is available in more than 30 different languages.

\subsubsection{Issues in Xender}

During the analysis phase, the focus was also made on the issues related to the Xender file sharing application. These issues are listed below:

- Data Transmission Error may occur sometimes.

- Creating a group for file sharing may give rise to issues.

- Joining pre existing group for sharing data may have some issues

\section{COMPARATIVE ANALYSIS OF FILE SHARING APPLICATIONS}

\subsection{Comparison based on different features}

In this section, the file sharing applications namely SHAREit, Zapya and Xender has been compared, which are discussed in earlier section.

Table 1 show the comparison of these file sharing applications based on different features like Number of active users worldwide, Devices supported on which these applications can run, Services these file sharing applications provide.

Table 1. Comparison of SHAREit, Zapya and Xender

\begin{tabular}{|c|c|c|c|}
\hline Features & SHAREit & Zapya & Xender \\
\hline $\begin{array}{l}\text { No. Of } \\
\text { Users }\end{array}$ & $\begin{array}{l}\text { Over } 700 \\
\text { Million. }\end{array}$ & $\begin{array}{l}\text { Over } 450 \\
\text { Million. }\end{array}$ & $\begin{array}{l}\text { Over } 330 \\
\text { Million. }\end{array}$ \\
\hline $\begin{array}{l}\text { Device } \\
\text { Supported }\end{array}$ & $\begin{array}{l}\text { Android, IOS, } \\
\text { Mac \& } \\
\text { Windows }\end{array}$ & $\begin{array}{l}\text { Android, IOS, } \\
\text { MacOS \& } \\
\text { Windows }\end{array}$ & $\begin{array}{l}\text { Android, } \\
\text { Windows, } \\
\text { Mac \& IOS }\end{array}$ \\
\hline \multirow{2}{*}{ Services } & $\begin{array}{l}\text { Cross-platform } \\
\text { file sharing }\end{array}$ & $\begin{array}{l}\text { Cross Platform } \\
\text { Data Sharing and } \\
\text { Data Backup }\end{array}$ & $\begin{array}{l}\text { SHAKE } \\
\text { option for data } \\
\text { transfer }\end{array}$ \\
\hline & $\begin{array}{l}\text { CONTROL \& } \\
\text { CLONEit }\end{array}$ & Replicate Phone & Connect PC \\
\hline
\end{tabular}

\subsection{Comparison based on file sharing time}

In this Section, the file sharing applications (SHAREit, Zapya and Xender) has been compared based on their file sharing rate for different types of files and of different sizes. The result is presented in Table $2 \&$ Table 3.

Table 2. Transfer Rate for different types of files and of different sizes.

\begin{tabular}{|c|c|c|c|}
\hline File Type & SHAREit & Zapya & Xender \\
\hline $\begin{array}{c}\text { Single } \\
\text { Small File }\end{array}$ & $\begin{array}{c}1 \text { file } \\
(4.2 \mathrm{Mb}) \text { in } \\
1 \mathrm{sec}\end{array}$ & $\begin{array}{c}1 \mathrm{file} \\
(5.5 \mathrm{Mb}) \text { in } \\
1 \mathrm{sec}\end{array}$ & $\begin{array}{c}1 \text { file } \\
(5.2 \mathrm{Mb}) \text { in } \\
1.12 \mathrm{secs}\end{array}$ \\
\hline $\begin{array}{l}\text { Multiple } \\
\text { Small } \\
\text { Files }\end{array}$ & $\begin{array}{c}21 \text { files } \\
(19.3 \mathrm{Mb}) \text { in } \\
19 \text { secs }\end{array}$ & $\begin{array}{c}76 \text { files } \\
(15.12 \mathrm{Mb}) \text { in } \\
10 \mathrm{sec}\end{array}$ & $\begin{array}{c}30 \text { files } \\
(10.4 \mathrm{Mb}) \text { in } \\
2.4 \text { secs }\end{array}$ \\
\hline $\begin{array}{l}\text { Single Big } \\
\text { File }\end{array}$ & $\begin{array}{c}1 \text { file } \\
(899 \mathrm{Mb}) \text { in } \\
3 \min 2 \mathrm{secs} \\
(182 \mathrm{secs})\end{array}$ & $\begin{array}{c}1 \text { file } \\
(653 \mathrm{Mb}) \text { in } \\
2 \mathrm{~min} 58 \mathrm{secs} \\
(178 \mathrm{secs})\end{array}$ & $\begin{array}{c}1 \text { file } \\
(890 \mathrm{Mb}) \text { in } \\
3 \text { min22secs } \\
(202 \text { secs })\end{array}$ \\
\hline $\begin{array}{l}\text { Multiple } \\
\text { Big Files }\end{array}$ & $\begin{array}{c}10 \text { files } \\
(591.1 \mathrm{Mb}) \text { in } \\
2 \text { min } 12 \mathrm{secs} \\
(132 \mathrm{secs})\end{array}$ & $\begin{array}{l}22 \text { files } \\
(980 \mathrm{Mb}) \text { in } \\
3 \mathrm{mins} \\
(180 \mathrm{secs})\end{array}$ & $\begin{array}{c}20 \text { files } \\
(840 \mathrm{Mb}) \text { in } \\
2 \text { min } 38 \text { secs } \\
(218 \text { secs })\end{array}$ \\
\hline
\end{tabular}


Analysis for sharing different files through SHAREit, Zapya \& Xender based on File Sharing transfer rate as shown in Figure 5 can be given as follows;

For Single Small File - SHAREit, Zapya and Xender are evenly matched and there is very minute difference while sharing small files.

For Multiple Small Files - Xender is comparatively better than Zapya and SHAREit and shares with high speed. Zapya and SHAREit are comparatively slow while sharing multiple small files.

For Single Big File - SHAREit is comparatively better than Zapya and Xender while sharing single big file.

For Multiple Big Files - Zapya is comparatively better than SHAREit and Xender while sharing multiple big files.

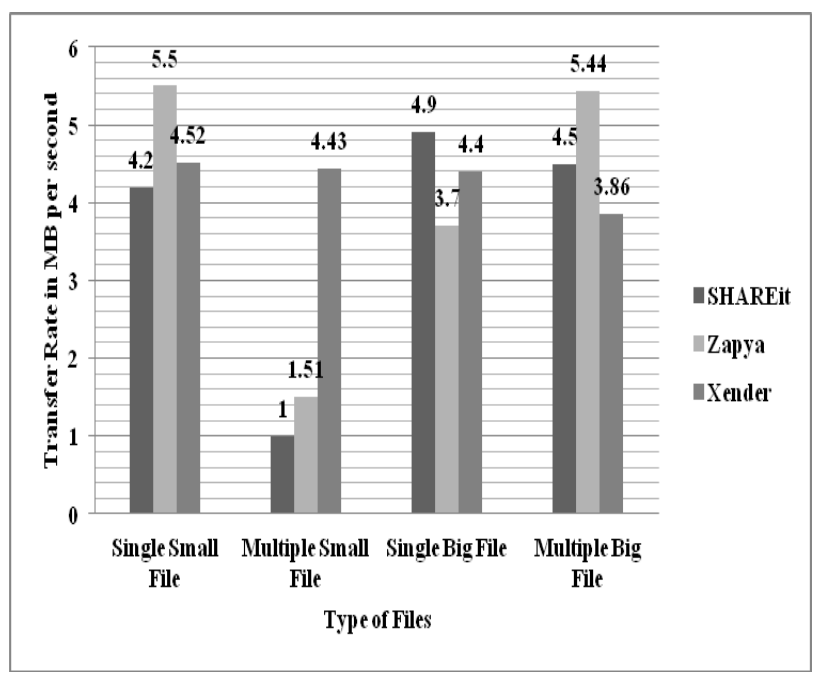

Fig 5: Transfer Rate for different type of files of different sizes

Table 3. Transfer Rate for same types of files of same size

\begin{tabular}{|c|c|c|c|}
\hline File Type & SHAREit & Zapya & Xender \\
\hline $\begin{array}{l}\text { Single Small } \\
\text { File } \\
\text { (File Size- } \\
10.2 \mathrm{Mb} \text { ) }\end{array}$ & In 3 secs & In 3 secs & In 3 secs \\
\hline $\begin{array}{l}\text { Multiple Small } \\
\text { Files } \\
\text { (File Size- } \\
243 \mathrm{Mb} \text { ) }\end{array}$ & In 54 secs & $\begin{array}{c}\text { In } \\
2 \min 16 \operatorname{secs} \\
(136 \mathrm{secs})\end{array}$ & In 50secs \\
\hline $\begin{array}{l}\text { Single Big File } \\
\text { (File Size- } \\
890 \mathrm{Mb} \text { ) }\end{array}$ & $\begin{array}{c}\text { In } \\
\text { 2min54secs } \\
\text { (174secs) }\end{array}$ & $\begin{array}{c}\text { In } \\
\text { 3min9secs } \\
\text { (189secs) }\end{array}$ & $\begin{array}{c}\text { In } \\
\text { 3min53secs } \\
\text { (233secs) }\end{array}$ \\
\hline $\begin{array}{l}\text { Multiple Big } \\
\text { File } \\
\text { (File Size- } \\
1.51 \mathrm{~Gb} \text { ) }\end{array}$ & $\begin{array}{c}\text { In } \\
\text { 4min36secs } \\
\text { (276secs) }\end{array}$ & $\begin{array}{c}\text { In } \\
\text { 7min11secs } \\
\text { (431secs) }\end{array}$ & $\begin{array}{c}\text { In } \\
\text { 6min11secs } \\
\text { (371secs) }\end{array}$ \\
\hline
\end{tabular}

Analysis for sharing same files through SHAREit Zapya \& Xender based on file sharing transfer rate as shown in Figure 6 can be made as follows:
For Single Small File - SHAREit, Zapya and Xender are evenly matched and there is very minute difference while sharing small files.

For Multiple Small Files - Xender \& SHAREit is comparatively better than Zapya while sharing multiple small files.

For Single Big File - SHAREit is comparatively better than Zapya and Xender while sharing single big file.

For Multiple Big Files - SHAREit is comparatively better than Zapya and Xender while sharing multiple big files.

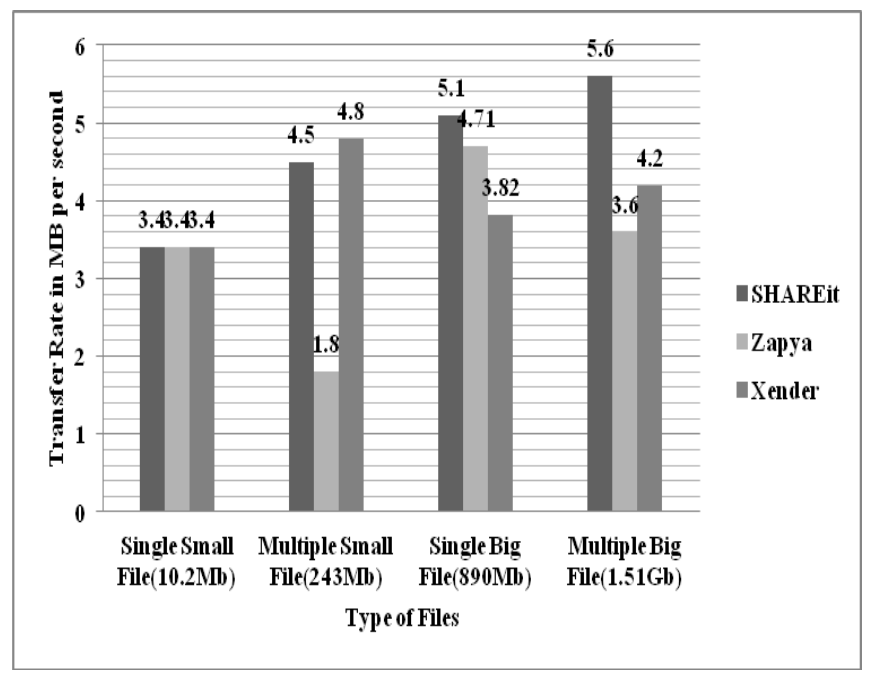

Fig 6: Transfer Rate for same types of files of same size

Table 4, shows the comparison between these file sharing applications SHAREit, Zapya \& Xender based on several features and comparison based on the security mechanism which are essential to ensure the security of the data and files such as confidentiality, integrity, and the authenticity of data which are being shared with others through these file sharing applications, and also to highlight the major security flaws and security concern which are present in these file sharing applications.

There is no authentication process for the users which are using these file sharing applications and sharing data with other users, no confidentiality is maintained while the sharing of files which can lead to non repudiation, no integrity checks like encryption decryption algorithms or hashing algorithms are used to ensure the integrity of the files while they are in devices or in transit which can lead to unauthorized access \& modification of data, and monitoring of files in transit.

Table 4. Comparison of SHAREit, Zapya \& Xender based on several parameters

\begin{tabular}{|c|c|c|c|c|}
\hline \multicolumn{2}{|c|}{ Features } & SHAREit & Zapya & Xender \\
\hline \multirow{3}{*}{$\begin{array}{c}\text { Compatible } \\
\text { Devices }\end{array}$} & Android & $\checkmark$ & $\checkmark$ & $\checkmark$ \\
\hline & $\mathrm{iOS}$ & $\checkmark$ & $\checkmark$ & $\checkmark$ \\
\hline & Windows & $\checkmark$ & $\checkmark$ & $\checkmark$ \\
\hline \multirow{3}{*}{$\begin{array}{c}\text { Security } \\
\text { Mechanism }\end{array}$} & Confidentiality & $x$ & $x$ & $x$ \\
\hline & Authentication & $x$ & $x$ & $x$ \\
\hline & Integrity & $x$ & $x$ & $x$ \\
\hline
\end{tabular}




\begin{tabular}{|c|c|c|c|c|}
\hline \multicolumn{2}{|c|}{ Remote Control of Device } & x & $\checkmark$ & $x$ \\
\hline \multirow{2}{*}{$\begin{array}{c}\text { File Sharing } \\
\text { Modes }\end{array}$} & Peer-to-Peer & $\checkmark$ & $\checkmark$ & $\checkmark$ \\
\cline { 2 - 5 } & Group & $x$ & $\checkmark$ & $\checkmark$ \\
\hline \multicolumn{2}{|c|}{ Compression } & $x$ & $x$ & $\checkmark$ \\
\hline \multicolumn{2}{|c|}{ Encryption } & $\boldsymbol{x}$ & $\boldsymbol{x}$ & $\boldsymbol{x}$ \\
\hline \multicolumn{2}{|c|}{} \\
\hline
\end{tabular}

\subsection{Findings based on Research \& Analysis of the file sharing applications}

Based on the study and transfer test results, the following analysis has been made;

- While file is been shared among sender and receiver, all data services like mobile data or Wi-Fi connectivity is disabled till both sender and receiver are connected to WLAN network created for file sharing.

- Both devices (Sender \& Receiver) should have identical file sharing application for file sharing.

- Both devices (Sender \& Receiver) should have WLAN (Wi-Fi Hotspot) features enabled device to use these file sharing applications.

- Both devices (Sender \& Receiver) should stay within the WLAN network's range created for file sharing. Even if either one of the two devices moves out from the WLAN network range, then file sharing will abort and fail.

- If file sharing was interrupted for some reason then in SHAREit application it will resume file sharing from the point of interruption earlier.

- In SHAREit, if a device (user) is in receiving mode, then the (receiving device) Receiver will create an ad-hoc WLAN (Wi-Fi Hotspot) network and anyone within the range can send file to that user (receiving device) by connecting to that same network, as SHAREit does not use any security mechanism to ensure authenticity and confidentiality of sender and receiver.

\section{FUTURE WORK}

As a part of future work, the focus has been made on to the issues commonly faced in these file sharing applications.

Specifically, as in SHAREit, there is no security mechanism for authentication and confidentiality of sender and receiver. This issue can be resolved by employing pass-key or establishing a secure session key prior to file sharing.

Another issue in the mentioned file sharing applications is that files are not encrypted prior to sharing and also unencrypted data is shared with between sending \& receiving devices. Encryption Decryption algorithms and Hashing algorithms should be implemented with these file sharing may indulge additional complexity with the process and make it more time consuming as to encrypt the data prior to transfer and them decrypt the received data and then match the hash value of the received data. However, it is not present in these file sharing applications.

\section{CONCLUSION}

In this paper, the research has been focused on the file sharing applications running on Smartphone's specifically android mobile devices. File sharing applications use WLAN for sharing files faster among the connected devices. Demonstration has been performed by conducting file sharing on android mobile device using these popular mobile file sharing applications namely SHAREit, Xender \& Zapya. By transferring of all types of files such as single small file, single big file, multiple small and big files has been performed to compare the file transfer rate among these file sharing applications. Different analysis has been performed focusing on ease of access and compatibility and the results obtained were presented.

However, these file sharing applications have issues related to security aspects such as confidentiality, authentication, integrity etc.

Being widely used and supported by big corporate giants, these file sharing applications can be upgraded to provide additional security mechanisms by providing these security mechanism with these file sharing applications in the future and it will make file sharing using WLAN secure and reliable by ensuring the authenticity of the user which enable only the legitimate users (device) for sharing files, and by ensuring the confidentiality of the users (devices) to ensure that only the authorized user to share data, and by providing the integrity of the data while they are stored in devices prior to file sharing or while in transit by enabling Encryption Decryption algorithm and hashing algorithm to ensure that the files and data are not tampered and changed and they file received are same as the file sent.

By enabling these security mechanism file sharing through WLAN (Wi-Fi Hotspot) will be made more secure and more reliable in the future.

\section{REFERENCES}

[1][Online] http://thehub.smsglobal.com/smartphoneownership-usage-and-penetration

[2][Online]http://www.uSHAREit.com/?referer=gp\&app=shar eit

[3] [Online] http://www.izapya.com/

[4] [Online] http://www.xender.com/

[5] [Online] http://shareit.lenovo.com/

[6] [Online] https://zapya.org/

[7] [Online] http://xender.en.uptodown.com/android 